\title{
First archeointensity results from Portuguese potteries (1550-1750 AD)
}

\author{
Gelvam A. Hartmann ${ }^{1}$, Ricardo I. F. Trindade ${ }^{1}$, Avto Goguitchaichvili ${ }^{2,3}$, \\ Carlos Etchevarne ${ }^{4}$, Juan Morales ${ }^{2,3}$, and Marisa C. Afonso ${ }^{5}$ \\ ${ }^{1}$ Departamento de Geofísica, Instituto de Astronomia, Geofísica e Ciências Atmosféricas, Universidade de São Paulo, \\ Rua do Matão, 1226, 05508-090, São Paulo, Brazil \\ ${ }^{2}$ Laboratorio de Paleomagnetismo y Geofisica Nuclear, Instituto de Geofisica, Universidad Nacional Autónoma de México, \\ Ciudad Universitaria, 04510, México, DF, Mexico \\ ${ }^{3}$ Laboratorio Interinstitucional de Magnetismo Natural, Instituto de Geofisica, Universidad Nacional Autónoma de México, \\ Tzintzuntzan, 310, 58098, Morelia, Mexico \\ ${ }^{4}$ Departamento de Antropologia, Universidade Federal da Bahia, Terreiro de Jesus, \\ Prédio da Faculdade de Medicina, 40026-010, Salvador, Brazil \\ ${ }^{5}$ Museu de Arqueologia e Etnologia, Universidade de São Paulo, Av. Prof. Almeida Prado, 1466, 05508-090, São Paulo, Brazil
}

(Received November 22, 2007; Revised February 21, 2008; Accepted February 29, 2008; Online published January 23, 2009)

\begin{abstract}
Geomagnetic field variations at archeomagnetic timescales can be obtained from well-dated heated structures and archeological potsherds. Here, we present the first archeointensity results obtained on Portuguese ceramics (1550 to $1750 \mathrm{AD}$ ) collected at Brazilian archeological sites. The results are compared to those obtained from Western Europe and currently available geomagnetic field models. Continuous thermomagnetic and IRM acquisitions curves indicate that Ti-poor titanomagnetite is responsible for the remanence in these ceramic fragments. Five fragments (24 samples) out of twelve analyzed yielded reliable intensity estimates. The row archeointensity data were corrected for TRM anisotropy and cooling rate effect. The mean dipole moments are obtained for three different age intervals: $1550 \pm 30 \mathrm{AD}, 1600 \pm 30 \mathrm{AD}$ and $1750 \pm 50 \mathrm{AD}$. Mean intensities vary from $37.9 \pm 4.2 \mu \mathrm{T}$ to $54.8 \pm 7.6 \mu \mathrm{T}$ in agreement with the previously reported data for $1550 \mathrm{AD}$ and $1750 \mathrm{AD}$. Relatively weaker, but still highly dispersed, values were obtained for 1600 AD ceramics.
\end{abstract}

Key words: Archeointensity, secular variation, cooling rate correction, Portuguese pottery.

\section{Introduction}

The variations of the Earth's magnetic field at archeomagnetic timescales $\left(10^{2}\right.$ to several $10^{3}$ of years) can be obtained from well-dated heated structures and archeological potsherds. Directional and intensity data obtained from these materials have been used to produce reference curves for the past few millennia. Reference curves (also called master curves), which reveal the variations in the intensity of the geomagnetic field are now available for several regions, including North America, Meso-America, Eastern Asia, Eastern and Western Europe (e.g., Kovacheva, 1997; Yu et al., 2000; Morales et al., 2001; Bowles et al., 2002; Genevey et al., 2003; Soler-Arechalde et al., 2006; see also the compilations of Valet, 2003; Perrin and Schnepp, 2004; Korte et al., 2005). Archeointensity data for Western Europe are concentrated on archeological sites from France (e.g., Chauvin et al., 2000; Gallet et al., 2002; Genevey and Gallet, 2002; Gallet et al., 2005) while only few results are available for the Iberian Peninsula (Kovacheva et al., 1995; Gómez-Paccard et al., 2006). Although abundant archeological remains are available in Portugal and Brazil, archeomagnetic studies are almost nonexistent. Here we present the first archeointensity results obtained from Portuguese pottery. The principal aim of this study is to try to contribute

Copyright (c) The Society of Geomagnetism and Earth, Planetary and Space Sciences (SGEPSS); The Seismological Society of Japan; The Volcanological Society of Japan; The Geodetic Society of Japan; The Japanese Society for Planetary Sciences; TERRAPUB. to the reference archeointensity curve for Iberian Peninsula. Our results, which are limited to the 1550-1750 AD interval are compared to those obtained from Western Europe (Chauvin et al., 2000; Genevey and Gallet, 2002; Gallet et al., 2005; Gómez-Paccard et al., 2006) and to the available theoretical and statistical models of the geomagnetic field (Jackson et al., 2000; Korte and Constable, 2005).

\section{Archeological Context and Age Estimation}

The studied material was collected at the colonial archeological site of Sé, in Salvador, Northeast Brazil. Salvador was the first post-colonial capital established in South America while Sé represents a main catholic church at colonial times. Its construction started at 1552 and was concluded during the second half of the XVII century. The building, demolished in 1933, was placed at the border of a sea cliff in an unstable area. In an attempt to keep the building structure, several layers of ceramic fragments, including wall-tile (azulejos), faience, pottery, bricks and tiles were deposited at the border of the sea cliff. The stratigraphy of these deposits has been used to track the evolution of social and alimentary habits of the inhabitants of Salvador through the colonial period (Etchevarne, 2003). The decorative pottery, azulejos and faience collected in the Sé site have been produced in Portugal (Etchevarne, 2006). For the periods mentioned above, the greatest centers of ceramic production in Portugal were Lisbon, Vila Nova de GaiaPorto and Aveiro-Coimbra. The studied ceramics are proba- 

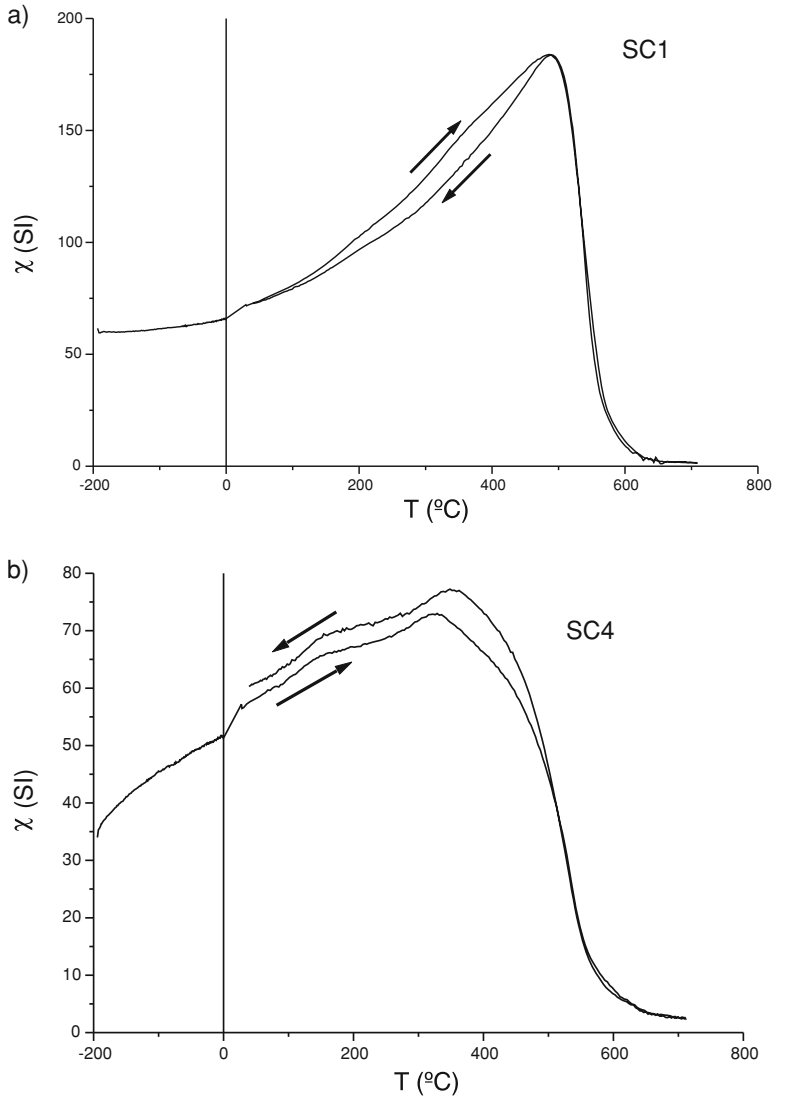

Fig. 1. Thermomagnetic curves for two representative samples of Portuguese ceramic collection. Low and high-temperature measurements were performed in the same sample. Susceptibility values were corrected from furnace signal.

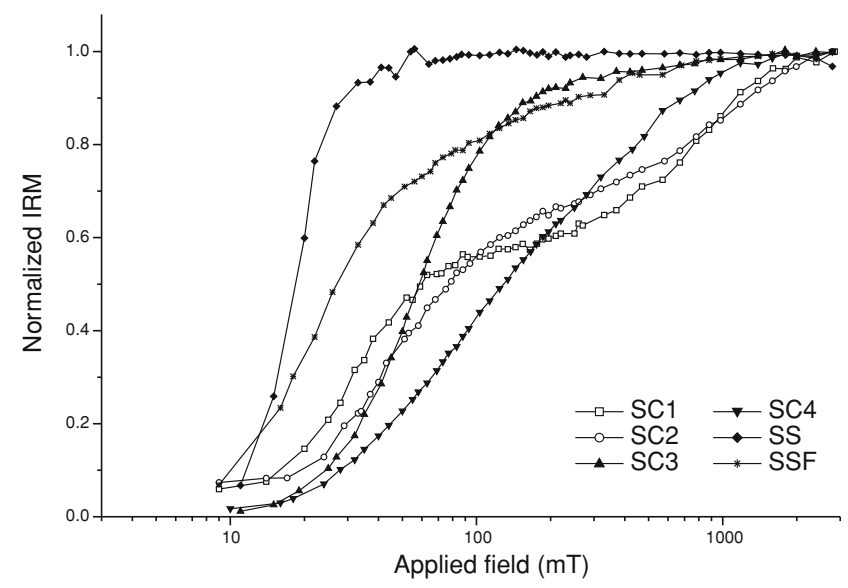

Fig. 2. IRM acquisition curves for six samples used in our analysis.

bly originated from one of these production centers. For this study we have selected 12 fragments of azulejos (1), faience (1), glazed ceramics (3) and decorative potteries (6) of Portuguese origin. We have included only one fragment of utilitarian pottery (the SC1 fragment) but keeping in mind that this material could have been re-heated. Bricks and tiles were avoided due to their likely Brazilian origin. A description of the analyzed fragments is given in Table 1 . The age of these potsherds was inferred archeologically, from written documentation and the ceramics style itself. Three main periods of production are identified: $1550 \pm 30 \mathrm{AD}$, $1600 \pm 30 \mathrm{AD}$ and 1750 $\pm 50 \mathrm{AD}$ (Etchevarne, 2006, 2007).

\section{Methods}

Paleointensity measurements were carried out at the paleomagnetic laboratories of the University of São Paulo (USP) and National University of Mexico (UNAM). Fragments analyzed in Mexico were inserted in ultrapure salt $(\mathrm{NaCl})$ pellets of $25 \mathrm{~mm}$ of diameter per $22 \mathrm{~mm}$ of height; an arbitrary orientation was given for each specimen. Remanent magnetization was measured with a JR-6 (Agico Ltd.) spinner magnetometer and thermal treatment was achieved by using a dual-chamber ASC furnace with $1 \mathrm{~h}$ heating cycles. Magnetization per unit volume of 'blank' pellets ranges on the order of $10^{-5} \mathrm{~A} / \mathrm{m}$, whereas magnetization of typical archeomagnetic cores prepared for archeointensity determinations ranges on the order of $10^{-2}$ to $10^{-1} \mathrm{~A} / \mathrm{m}$. Archeointensity experiments were carried out under air using the Thellier and Thellier (1959) method modified by Coe (1967). For each double-heating step, the samples were first partially demagnetized in zero-field, and then remagnetized in a laboratory inducing field $\left(H_{\mathrm{lab}}\right)$. Fragments analyzed in São Paulo were cut in cylinders of $8 \mathrm{~mm}$ of diameter per $10 \mathrm{~mm}$ of height. Remanent magnetization was measured with a $2 \mathrm{G}$-cryogenic magnetometer (2G Enterprises). Heating cycles of 45 minutes were performed in a modified MMTD-60 furnace (Magnetic Measurements Ltd.) that incorporates a water-cooling system. The paleointensity protocol used in São Paulo laboratory was that of Aitken et al. (1988). In this protocol, the samples are first partially remagnetized in a $H_{\text {lab }}$ and then demagnetized in zero-field. In both paleomagnetic laboratories, we have used a $H_{\text {lab }}$ of $30 \mu \mathrm{T}$. Same thirteen doubleheating steps from $200^{\circ} \mathrm{C}$ up to $550^{\circ} \mathrm{C}$ were employed. The pTRM checks were carried out after every two temperature steps in order to detect any magnetic alteration. Thermomagnetic curves were measured with a KLY4-CS3 (Agico Ltd.) susceptometer while a IRM (isothermal remanent magnetization) acquisition were performed using both a Pulse Magnetizer MMPM-10 (Magnetic Measurements Ltd.) and a Molspin spinner magnetometer (Molspin Ltd.). Both measurements were made at the University of São Paulo.

TRM anisotropy and cooling rate corrections were performed on all samples. The TRM anisotropy tensor represents the preferential alignment of magnetic carriers produced by stretching of clay when ceramics were molded. Chauvin et al. (2000) and Genevey and Gallet (2002) showed that the correction for TRM is very important in order to obtain reliable intensity values in pottery samples. The TRM anisotropy tensor was obtained after the paleointensities measurements by the acquisition of six pTRMs in different positions: $X,-X, Y,-Y, Z$ and $-Z$. After each measurement, one diagonal term and two symmetric terms $\left(K_{1 j}, K_{2 j}, K_{3 j}, j=1,2,3\right)$ of the tensor are obtained. Subsequently, $K_{i j}(i \neq j)$ terms are replaced by $\left(K_{i j} / K_{j i}\right) / 2$ terms and eigenvalues and the TRM anisotropy tensor is calculated. The TRM anisotropy was applied on samples showing less than $20 \%$ of variation of the TRM acquisition capacity (see below). The TRM anisotropy was performed 


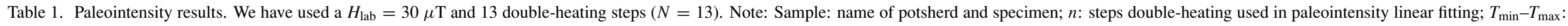
interval temperatures used in intensity estimates; $f$ : NRM fraction; $g$ : gap factor; $q$ : quality factor; $H_{\mathrm{a}} \pm \sigma$ (UC): ancient field and error uncorrected; $H_{\mathrm{a}} \pm$ sd (UC): intensity mean and standard deviation before corrections; $H_{\mathrm{a}}$ (ANI): ancient field after TRM anisotropy correction; $F_{\text {corr }}(\%)$ : correction factor of cooling rate; $F_{\text {alt }}(\%)$ : alteration factor of cooling rate; $H_{\mathrm{a}}(\mathrm{CRC})$ : ancient field after cooling rate correction; $H_{\mathrm{a}} \pm$ sd $($ Corr): intensity

\begin{tabular}{|c|c|c|c|c|c|c|c|c|c|c|c|c|c|}
\hline Sample & 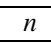 & $T_{\min }-T_{\max }$ & $f$ & $g$ & $q$ & $H_{\mathrm{a}} \pm \sigma(\mathrm{UC})$ & $H_{\mathrm{a}} \pm \mathrm{sd}(\mathrm{UC})$ & $H_{\mathrm{a}}(\mathrm{ANI})$ & $F_{\text {corr }}(\%)$ & $F_{\text {alt }}(\%)$ & $H_{\mathrm{a}}(\mathrm{CRC})$ & $H_{\mathrm{a}} \pm \mathrm{sd}$ (Corr) & VADM \\
\hline \multicolumn{14}{|c|}{ SC3 [1520-1580 AD]-Description: white azulejo fragment of $4 \mathrm{~cm}^{2}$ and $1 \mathrm{~cm}$ in thickness, made of fine-grained ceramic. } \\
\hline $\mathrm{SC} 3-\mathrm{S} 1$ & 9 & $250-520$ & 0.43 & 0.85 & 5.93 & $60.3 \pm 3.7$ & $56.3 \pm 6.1$ & 59.0 & -0.22 & -2.71 & 59.0 & $54.8 \pm 7.6$ & 12.4 \\
\hline SC3-S5 & 9 & $375-550$ & 0.42 & 0.86 & 9.20 & $49.3 \pm 2.0$ & & - & -6.70 & 0.77 & 46.0 & & \\
\hline SC3-S6 & 11 & $250-550$ & 0.46 & 0.87 & 7.28 & $59.3 \pm 3.3$ & & 51.6 & 0.91 & 3.20 & 59.3 & & \\
\hline \multicolumn{14}{|c|}{$\begin{array}{l}\text { SC1 }[1570-1630 \mathrm{AD}]-\text { Description: brick-red ceramic fragment of } 8 \mathrm{~cm}^{2} \text { and } 0.5 \mathrm{~cm} \text { in thickness made of fine-grained clay matrix with } 15-20 \% \text { of medium to coarse } \\
\text { sand fragments of quartz. It is the edge of a utilitarian potsherd. }\end{array}$} \\
\hline SC1-S1 & 13 & $20-550$ & 0.83 & 0.88 & 33.68 & $42.3 \pm 0.9$ & $43.4 \pm 5.5$ & 37.1 & -11.55 & -1.08 & 32.8 & $37.9 \pm 4.2$ & 8.58 \\
\hline $\mathrm{SC} 1-\mathrm{S} 2$ & 13 & $20-550$ & 0.88 & 0.89 & 46.11 & $48.6 \pm 0.8$ & & 45.8 & -10.45 & 1.20 & 41.0 & & \\
\hline $\mathrm{SC} 1-\mathrm{S} 3$ & 13 & $20-550$ & 0.88 & 0.86 & 32.60 & $46.3 \pm 1.1$ & & 43.3 & -9.31 & 1.10 & 39.3 & & \\
\hline SC1-S4 & 13 & $20-550$ & 0.86 & 0.90 & 32.07 & $33.1 \pm 0.8$ & & 35.5 & -7.35 & 1.90 & 32.9 & & \\
\hline SC1-S5 & 13 & $20-550$ & 0.89 & 0.87 & 40.91 & $43.5 \pm 0.8$ & & 42.3 & -8.76 & 0.56 & 38.6 & & \\
\hline SC1-S6 & 12 & $20-540$ & 0.90 & 0.89 & 27.06 & $46.7 \pm 1.4$ & & 42.9 & -0.53 & 2.59 & 42.9 & & \\
\hline \multicolumn{14}{|c|}{$\begin{array}{l}\text { SC4 [1570-1630 AD]-Description: glazed ceramic fragment of } 10 \mathrm{~cm}^{2} \text { and } 0.8 \mathrm{~cm} \text { in thickness with green glass coating over light-pink ceramic made of fine-grained clay } \\
\text { matrix with } 20-25 \% \text { of medium sand fragments of quartz and ceramic. It is part of the flank of a large, decorative pottery. }\end{array}$} \\
\hline SC4-S1 & 12 & $20-540$ & 0.96 & 0.79 & 47.98 & $39.8 \pm 0.6$ & $49.9 \pm 9.2$ & 34.6 & -5.05 & -0.67 & 32.9 & $42.5 \pm 8.6$ & 9.6 \\
\hline SC4-S3 & 12 & $20-540$ & 0.98 & 0.71 & 59.83 & $57.7 \pm 0.7$ & & 50.3 & -1.99 & -0.68 & 49.3 & & \\
\hline SC4-S5 & 12 & $20-540$ & 1.00 & 0.73 & 32.13 & $52.3 \pm 1.2$ & & 45.4 & -0.77 & -0.47 & 45.4 & & \\
\hline \multicolumn{14}{|c|}{$\begin{array}{l}\mathrm{SC} 2 \text { [1570-1630 AD]-Description: glazed ceramic fragment of } 8 \mathrm{~cm}^{2} \text { and } 0.6 \mathrm{~cm} \text { in thickness with green and yellow glass coating over light-pink ceramic made of fine-grained clay } \\
\text { matrix with } 15-20 \% \text { of fine to coarse sand fragments of quartz and ceramic. It is part of a decorative pottery }\end{array}$} \\
\hline $\mathrm{SC} 2-\mathrm{S} 1$ & 13 & $20-550$ & 0.94 & 0.89 & 24.01 & $48.1 \pm 1.7$ & $43.7 \pm 6.6$ & 45.4 & 0.66 & 1.69 & 45.4 & $44.8 \pm 6.2$ & 10.1 \\
\hline $\mathrm{SC} 2-\mathrm{S} 2$ & 8 & $20-450$ & 0.62 & 0.79 & 20.59 & $43.4 \pm 1.1$ & & - & -0.38 & 3.34 & 43.4 & & \\
\hline $\mathrm{SC} 2-\mathrm{S} 3$ & 12 & $20-540$ & 0.82 & 0.89 & 20.12 & $38.8 \pm 1.4$ & & 39.8 & 4.66 & 0.17 & 41.7 & & \\
\hline $\mathrm{SC} 2-\mathrm{S} 4$ & 12 & $20-540$ & 0.96 & 0.67 & 22.73 & $53.2 \pm 1.5$ & & 56.4 & -2.22 & 0.19 & 55.1 & & \\
\hline SC2-S5 & 13 & $20-550$ & 0.88 & 0.90 & 21.46 & $34.5 \pm 1.3$ & & 35.2 & 3.96 & 2.08 & 36.6 & & \\
\hline SC2-S6 & 12 & $20-540$ & 0.94 & 0.83 & 29.12 & $44.6 \pm 1.2$ & & 46.4 & -0.53 & 0.63 & 46.4 & & \\
\hline \multicolumn{14}{|c|}{$\begin{array}{l}\text { SSF [1700-1800 AD]—Description: portuguese faiance fragment of } 10 \mathrm{~cm}^{2} \text { and } 0.5 \mathrm{~cm} \text { in thickness with white glass coating over fine-grained yellow ceramic. } \\
\text { It is the edge of a plate. }\end{array}$} \\
\hline SSF-S1 & 10 & $250-540$ & 0.65 & 0.86 & 20.95 & $45.3 \pm 1.2$ & $47.2 \pm 4.5$ & 42.2 & -12.47 & 7.70 & 36.9 & $39.6 \pm 2.6$ & 8.97 \\
\hline SSF-S2 & 11 & $200-540$ & 0.68 & 0.88 & 12.56 & $48.1 \pm 2.3$ & & 45.4 & -10.12 & 9.33 & 40.8 & & \\
\hline SSF-S3 & 11 & $200-540$ & 0.58 & 0.86 & 10.31 & $54.8 \pm 2.7$ & & 49.1 & -12.24 & 7.59 & 43.1 & & \\
\hline SSF-S4 & 10 & $250-540$ & 0.64 & 0.86 & 9.85 & $48.5 \pm 2.7$ & & - & -13.95 & 7.46 & 41.7 & & \\
\hline SSF-S5 & 10 & $250-540$ & 0.67 & 0.85 & 12.70 & $41.9 \pm 1.9$ & & 43.4 & -13.81 & 5.64 & 37.4 & & \\
\hline SSF-S6 & 12 & $20-540$ & 0.85 & 0.86 & 7.63 & $44.5 \pm 4.3$ & & - & -15.01 & 5.40 & 37.8 & & \\
\hline
\end{tabular}


a) SS-S1

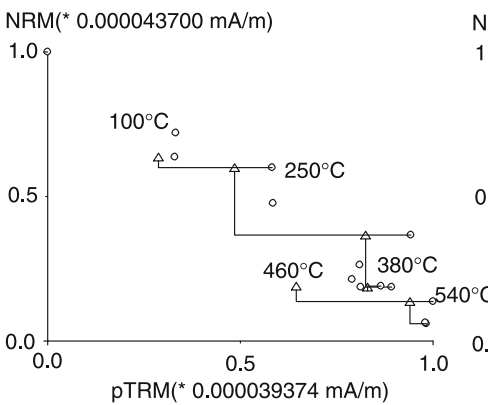

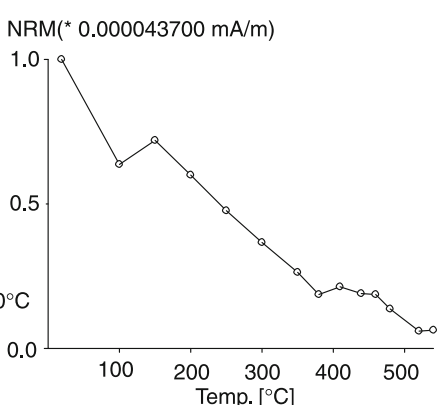

b) SSI-S5
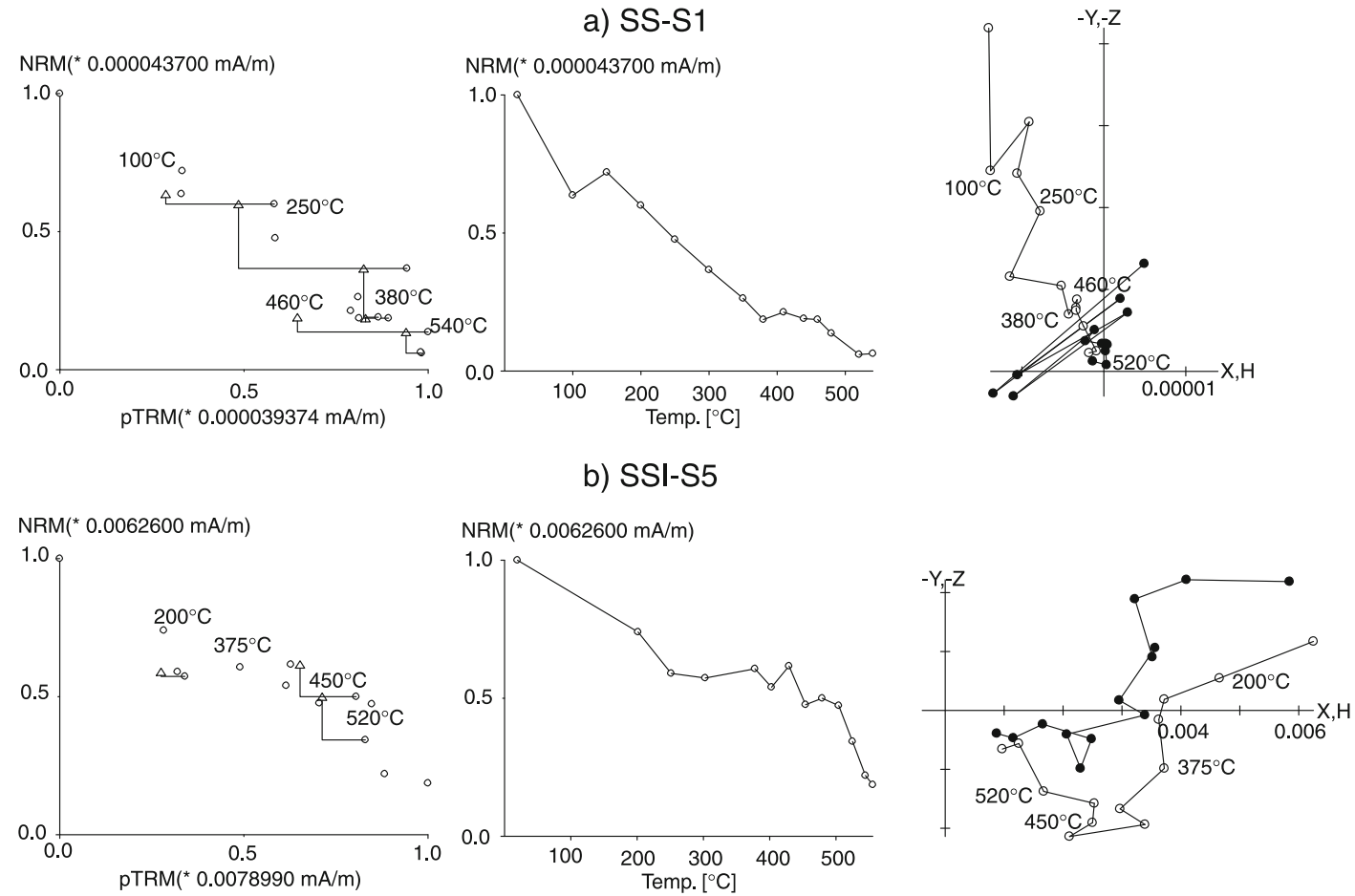

c) SQT-S1
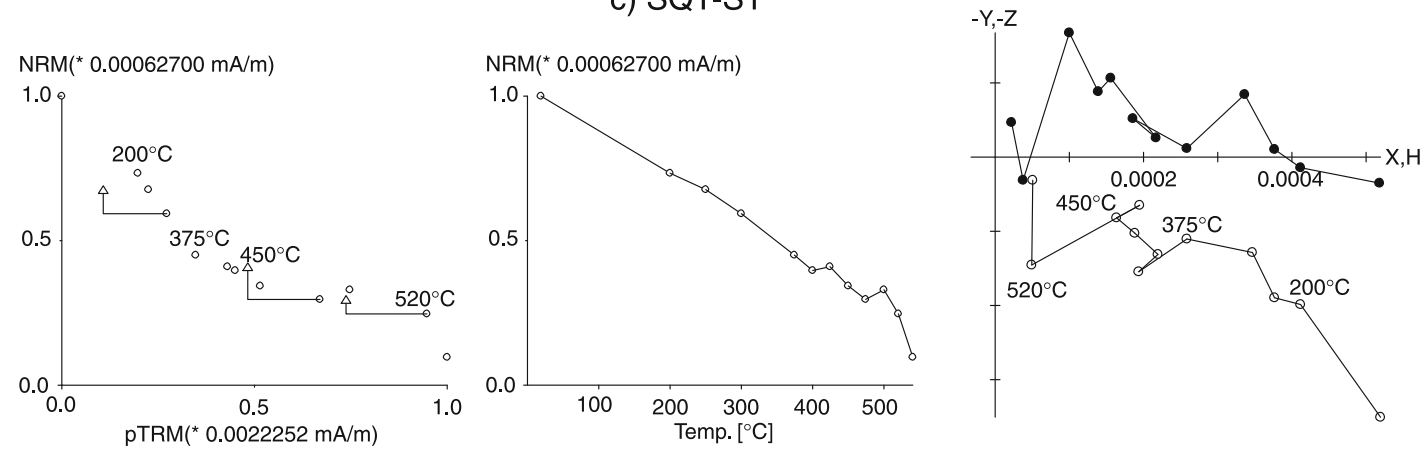

Fig. 3. NRM-TRM, decay and orthogonal vector plots corresponding to the rejected data: erratic behavior ((a) and (b)) and so-called concave-up behavior (c). Sample SS-S1 was analyzed in the USP lab, whereas samples SSI-S5 and SQT-S1 were analyzed in the UNAM lab.

after the archeointensity measurements (on a temperature of $550^{\circ} \mathrm{C}$ ), when $\sim 70 \%$ to $\sim 95 \%$ of NRM was removed.

Cooling rate dependence was theoretically reported by Néel (1955) for single-domain grains. This effect consists of a progressive increase of TRM intensity with the decrease of the cooling rate. For laboratory cooling times this effect is significant in potteries (e.g., Fox and Aitken, 1980; Chauvin et al., 2000) and occasionally for rock samples as well (Morales et al., 2006). In order to quantify the cooling rate effect, we carried out three in-field heatings after the paleointensity measurements: (a) fast-cooling ( $\sim 1 \mathrm{~h})$, (b) slow-cooling ( $\sim 20 \mathrm{~h})$ and (c) fast-cooling $(\sim 1 \mathrm{~h})$ again. The cooling rate correction factor is obtained from the difference between the slow-cooling step and the first fast-cooling step. The alteration factor is defined by difference between first and second fast-cooling steps; this factor indicates the magnetic alterations which occur during the archeointensity experiments. We corrected the intensity estimates for cooling rate effects when the correction factor was bigger than the alteration factor (e.g., Gómez-Paccard et al., 2006).

\section{Results}

\subsection{Magnetic mineralogy}

Thermomagnetic curves were carried out on selected samples in order to access the thermal stability and Curie temperatures of magnetic carriers. We have performed in air low-field susceptibility measurements from $-194^{\circ} \mathrm{C}$ up to $700^{\circ} \mathrm{C}$ on all 12 fragments. The thermomagnetic curves showed that the Curie temperature of magnetic carriers varies from $560^{\circ} \mathrm{C}$ up to $585^{\circ} \mathrm{C}$ (Fig. 1), indicating low-Ti titanomagnetite to pure magnetite in our samples. Some samples also show a small fraction of hematite. Thermomagnetic curves also revealed a reasonably high thermal stability and reversibility suggesting minor mineralogical changes during heating. This behavior is favorable for paleointensity determinations.

IRM acquisitions were made on 6 representative samples of the 12 studied fragments. Figure 2 shows IRM acquisitions for samples of SC1, SC2, SC3, SC4, SS and SSF fragments. Three different behaviors are distinguished from IRM curves. Three samples (SC3, SS, SSF) reach the saturation at fields between $0.1 \mathrm{~T}$ and $0.3 \mathrm{~T}$, indicat- 
a) $\mathrm{SC} 1-\mathrm{S} 2$
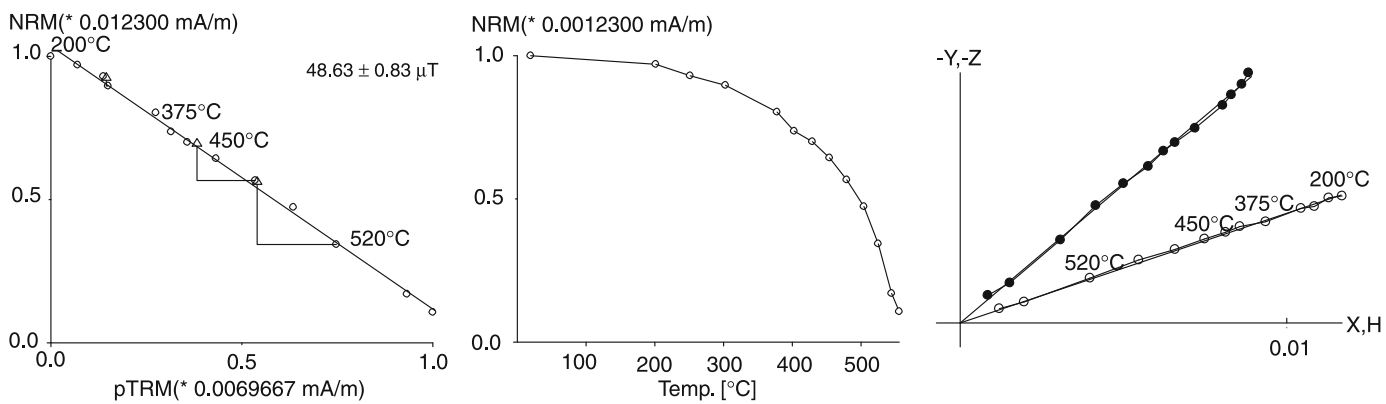

b) $\mathrm{SC} 1-\mathrm{S} 4$
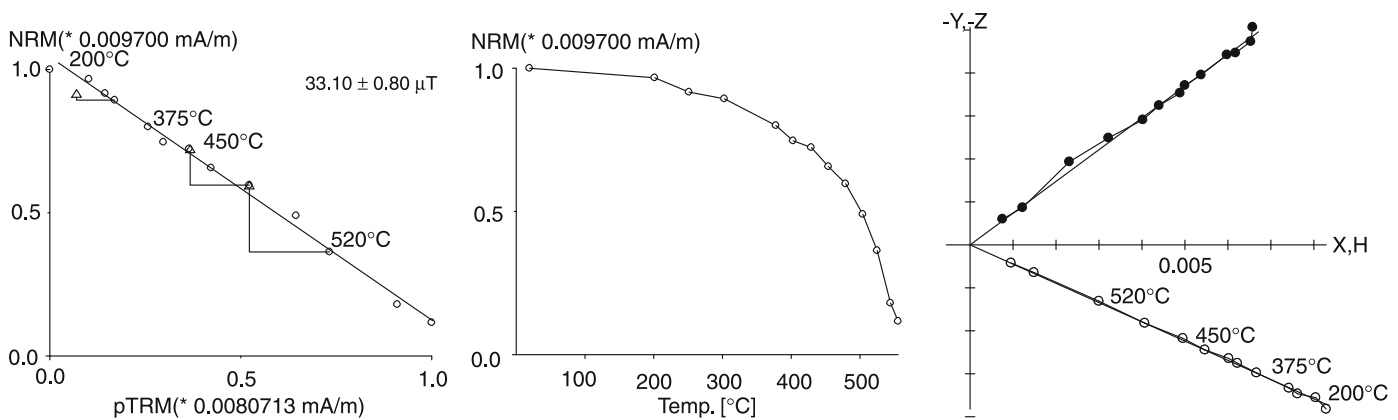

c) $\mathrm{SC} 2-\mathrm{S} 1$
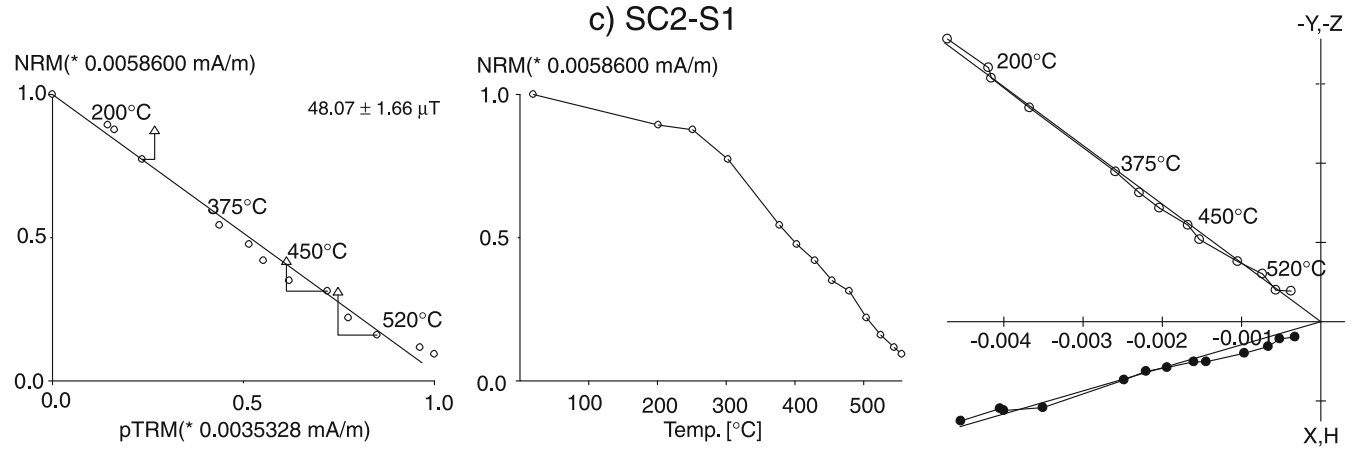

d) SC2-S5
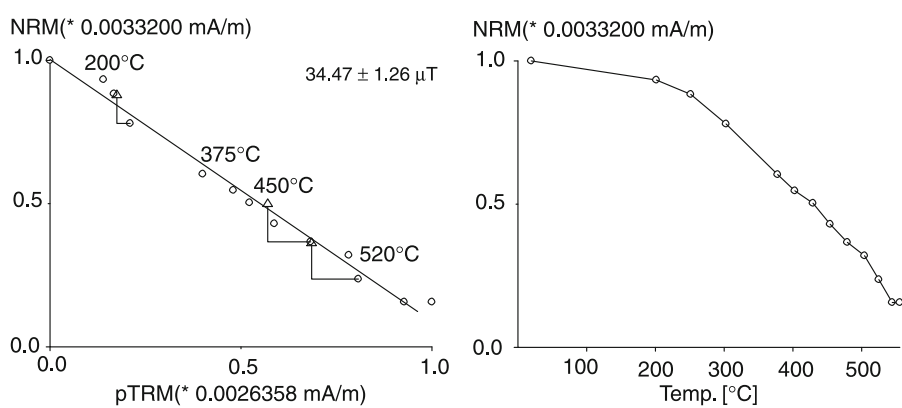

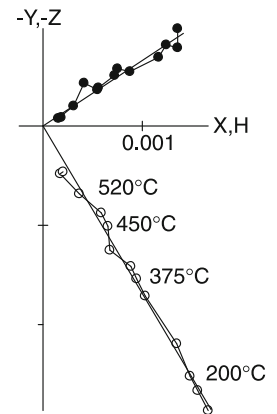

Fig. 4. NRM-TRM, decay and orthogonal vector plots for eight representative samples.

ing that their magnetization is carried by pseudo-singledomain spinel phases-most probably magnetite or titanomagnetite. A single sample (SC4) reaches saturation magnetization at fields $>1.2 \mathrm{~T}$, indicating the presence of some antiferromagnetic contribution. The high thermal stability observed on the thermomagnetic curve (Fig. 1(b)) is suggestive of a substituted hematite phase as recently reported by McIntosh et al. (2007). Other two samples (SC1 and
SC2) show a mixed behavior indicating the coexistence of (titano)magnetite and (titano)hematite.

\subsection{Archeointensity}

Unfortunately, all archeointensity experiments performed in São Paulo laboratory failed (10 specimens of six different potsherds, mostly decorative pottery). The Arai diagrams were erratic (Fig. 3(a)) and no intensity value could be determined from these samples. Samples ana- 
e) SC3-S5

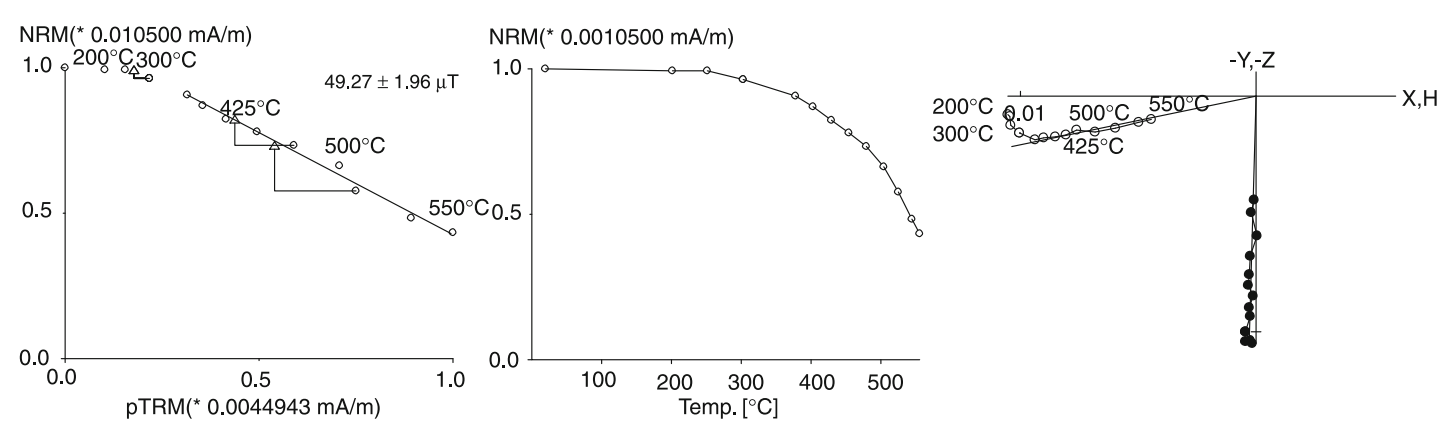

f) SC4-S1
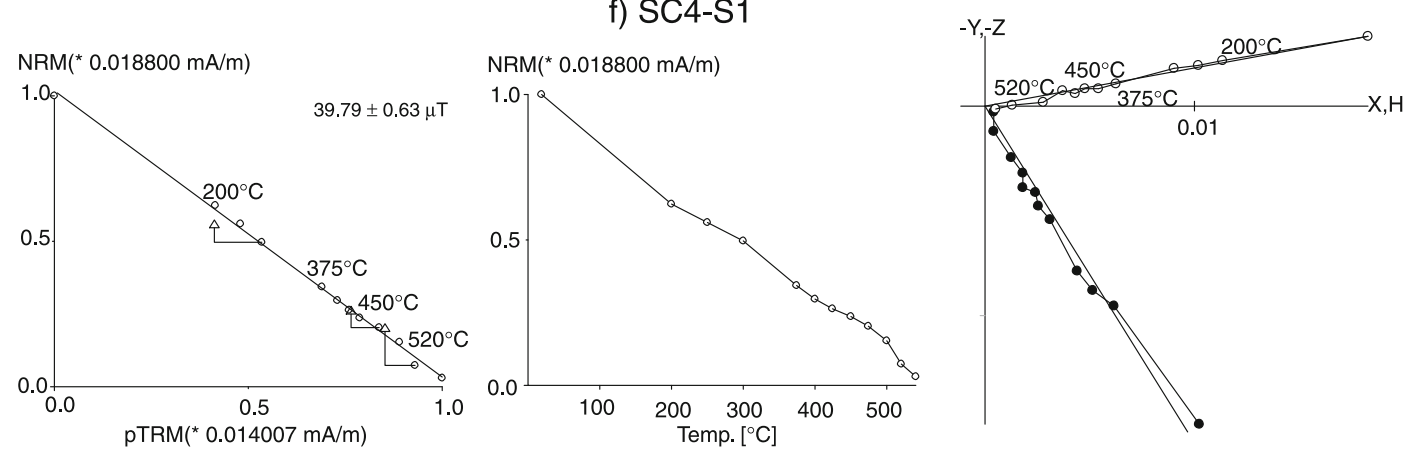

g) SC4-S3
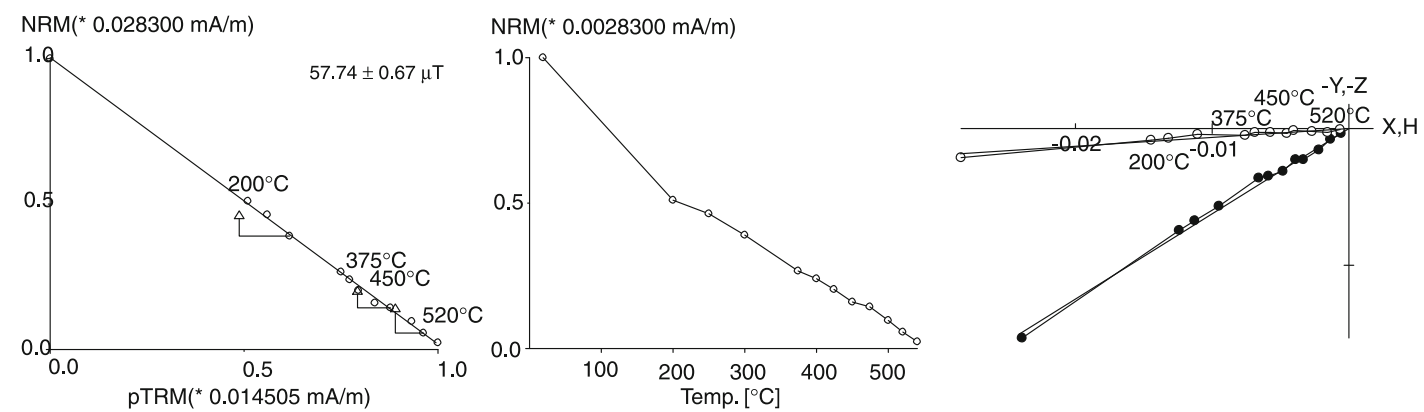

h) SSF-S1
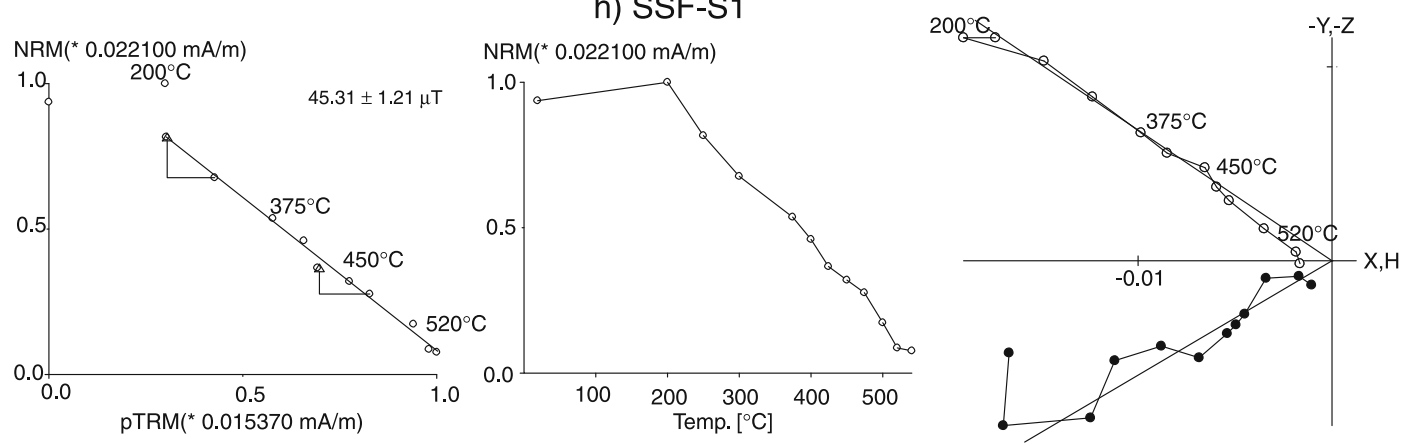

Fig. 4. (continued).

lyzed in the UNAM paleomagnetic laboratory comprise six sister-samples of those analyzed in São Paulo plus six other fragments. One-third of the 72 samples (belonging to 12 fragments) analyzed at UNAM gave reliable results. Rejected samples showed rather erratic behavior (Fig. 3(b)) or concave-up Arai plots (Fig. 3(c)). It is worth noting that all rejected sites correspond to fragments of brick-red coarse- grained ceramics, including most of the sister-samples of those analyzed in São Paulo. The only retained result obtained on this kind of material was that of site SC1, a fragment of utilitarian pottery.

Figure 4 shows examples of archeointensity estimates for five ceramic fragments that yielded acceptable results. NRM-TRM plots and associated orthogonal diagrams indi- 
cate a strong magnetic stability and linearity during almost whole paleointensity procedure. In some cases, however, we observe two components on the orthogonal diagrams. The first one is usually removed on temperatures below $350^{\circ} \mathrm{C}$ (for most of samples below to $250^{\circ} \mathrm{C}$ ). Such behavior probably characterizes a secondary viscous magnetic component. All intensity determinations were computed using the temperature interval of the primary (characteristic) remanent magnetization only.

Archeointensity data can be assessed by quality parameters. Table 1 shows the most reliable intensity results from these Portuguese potsherds. For each specimen, we indicate the temperature interval used in the intensity estimate, number of points ( $n$ ) used (at least five) and NRM fraction $(f)$ in the linear fitting, the $g$ (gap) and $q$ (quality) factors as defined by Coe et al. (1978). We have used at least $40 \%$ of NRM for paleointensity determinations with associated quality factor greater than 5 .

As mentioned above, the TRM anisotropy correction was applied in cases when the change in TRM acquisition capacity was lower than $20 \%$. Thus, following samples: SC2S2, SC3-S5, SSF-S4 and SSF-S6 were not corrected for the remanence anisotropy. In general, the studied samples show a rather high TRM anisotropy degree varying from 1.06 to 1.57 with no systematic predominance of prolate or oblate ellipsoids. Cooling rate experiments were carried out on all samples using a cooling time of about $20 \mathrm{~h}$. We note that so-called alteration factor was found systematically lower with respect to cooling rate correction. From our selected samples, only the SC3-S1, SC1-S6, SC4-S5, SC2-S1, SC2$\mathrm{S} 2$ and SC2-S6 were not corrected for cooling rate (see Table 1). After TRM anisotropy and cooling rate corrections, the intensity means vary from $37.9 \pm 4.2 \mu \mathrm{T}$ (SC1) up to $54.8 \pm 7.6 \mu \mathrm{T}$ (SC3).

\section{Discussion and Conclusion}

Generally speaking, the Portuguese potteries studied here showed a low success rate. But most of the fragments that failed archeointensity experiments, both in São Paulo and Mexico, were coarse-grained brick-red ceramic samples. Faience, glazed ceramic and azulejos showed $75 \%$ success in archeointensity determinations, indicating their great potential in recording the ancient field. Thermomagnetic curves show a high thermal stability during the heatings indicating that these materials are suitable for Thellier paleointensity experiments. Both $K-T$ and IRM acquisition curves demonstrate that the main magnetic carriers are pseudo-single-domain magnetite or low-Ti titanomagnetite. Five fragments yield reliable intensity estimates for three different age intervals $(1550 \pm 30 \mathrm{AD}, 1600 \pm 30$ $\mathrm{AD}$ and $1750 \pm 50 \mathrm{AD}$, Table 1). After cooling rate and anisotropy corrections the standard deviation of intensity values has been reduced for the three potsherds corresponding to $1600 \pm 30 \mathrm{AD}$ reinforcing the importance of these additional experiments for archeointensity determination. However, even after these corrections, there is still some dispersion between these potsherds (SC1, SC2 and SC4). There are two possible interpretations for the dispersion of archeointensity values for 1600 AD samples: either they correspond to a true dispersion, similar to the behavior observed by Gómez-Paccard et al. (2006) for seven values in Murcia (Spain), or they represent younger thermal remagnetization, since they correspond to displaced material from Portugal. In our case, we prefer the latter interpretation, since the lowest and most divergent value was obtained on the SC1 potsherd, which corresponds to brick-red utilitarian pottery, which could have been re-heated after its over-seas displacement. This sample is indicated in grey in Fig. 5 to differentiate it from samples SC2 and SC4, which correspond to decorative glazed ceramic fragments.

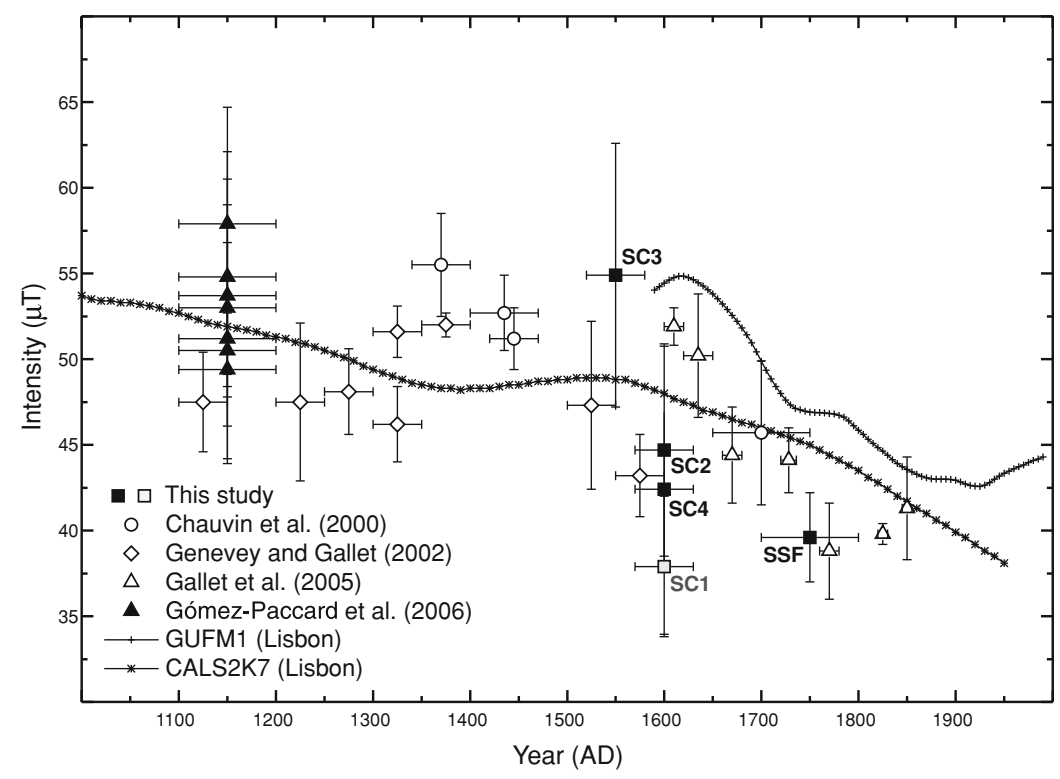

Fig. 5. Geomagnetic field intensity variation for Western Europe. All data were corrected for the latitude of Lisbon (see also the text). GUFM1 and CALS2K7 geomagnetic field models are from Jackson et al. (2000) and Korte and Constable (2005), respectively. The SC1 site was represented in grey since the archeointensity results were obtained on utilitarian pottery and could thus have been re-heated in Brazil. 
Figure 5 shows the geomagnetic field intensity evolution for the last millennium for Western Europe. We compared our results to a compilation of currently available data (Chauvin et al., 2000; Genevey and Gallet, 2002; Gallet et al., 2005; Gómez-Paccard et al., 2006) and to the geomagnetic field models of Jackson et al. (2000) and Korte and Constable (2005). Jackson et al. (2000) model starts at 1590 AD, whereas Korte and Constable curve encompasses the last 7000 years. At the beginning of the XII century, the intensity obtained from French and Spanish potteries present a large spread with mean values around $50 \mu \mathrm{T}$ at the latitude of Lisbon. These results are followed by a rapid increase in the field strength during the XIV and XV centuries up to $\sim 55 \mu \mathrm{T}$. For the second half of the XVI century, the intensity values fall back to $45 \mu \mathrm{T}-50 \mu \mathrm{T}$ values. Our data for this period provide $54.8 \pm 7.6 \mu \mathrm{T}$ paleointensities and agree with the geomagnetic field models of Jackson et al. (2000), but they are higher than the results from France obtained by Genevey and Gallet (2002). The archeointensity values of SC1, SC2 and SC4 potsherds (beginning of XVII century) are similar to the available experimental results obtained from France (Genevey and Gallet, 2002), but smaller than those of the geomagnetic field models of Korte and Constable (2005) and Jackson et al. (2000). In fact, they seem to reinforce the work of Gubbins et al. (2006) indicating a smaller $g_{0}^{1}$ coefficient at that time. The SSF site (XVII century) presents an intensity value near to the contemporary results obtained by Gallet et al. (2005). Both results are slightly lower than those predicted by the geomagnetic field models of Korte and Constable (2005) and Jackson et al. (2000).

The archeointensity results obtained for the first time on Portuguese ceramics are not numerous but they are of high quality, suggesting that the Portuguese pottery may be a suitable study target to establish a reference intensity curve for the Iberian Peninsula.

Acknowledgments. We are indebt to FAPESP (grant 05/577824, to G. A. Hartmann) and CNPq (Research Fellowship to R. I. F. Trindade, C. Etchevarne and M. C. Afonso). A. Goguitchaichvili is grateful for the financial support from CONACYT (grant 54957). We appreciate the constructive comments by E. Schnepp and M. Kovacheva that helped in improving this manuscript.

\section{References}

Aitken, M. J., A. L. Allsop, G. D. Bussell, and M. B. Winter, Determination of the intensity of the Earth's magnetic field during archaeological times: Reability of the Thellier technique, Rev. Geophys., 26, 3-12, 1988.

Bowles, J., J. Gee, J. Hildebrand, and L. Tauxe, Archaeomagnetic intensity results from California and Ecuador: evaluation of regional data, Phys. Earth Planet. Inter., 203(3-4), 967-981, 2002.

Chauvin, A., Y. Garcia, Ph. Lanos, and F. Laubenheimer, Paleointensity geomagnetic field recovered on archaeomagnetic sites from France, Phys. Earth Planet. Inter., 120, 111-136, 2000.

Coe, R. S., The determination of paleo-intensities of the Earth's magnetic field with emphasis on mechanisms which could cause non-ideal behavior in Thelier's method, J. Geomag. Geoelectr., 19, 157-179, 1967.

Coe, R. S., C. S. Gromm, and E. A. Mankinen, Geomagnetic paleointensities from radiocarbon dated lava flows on Hawaii and the question of the Pacific non-dipole low, J. Geophys. Res., 83, 1740-1756, 1978.
Etchevarne, C., A reciclagem da faiança em Salvador: contextos arqueológicos e tipos de utilização, Clio, 16, 2003.

Etchevarne, C., Aspectos da cerâmica colonial do século XVII, em Salvador, Bahia, Clio, 20, 2006.

Etchevarne, C., A faiança portuguesa do século XVII na Bahia. Patrimônio e Estudos, IPPAR, 10, 2007.

Fox, J. M. W. and M. J. Aitken, Cooling-rate dependence of thermoremanent magnetization, Nature, 283, 462-463, 1980.

Gallet, Y., A. Genevey, and M. LeGoff, Three millennia of direction variation of the Earth's magnetic field in Western Europe as revealed by archeological artefacts, Phys. Earth Planet. Inter., 131, 81-89, 2002.

Gallet, Y., A. Genevey, and F. Fluteau, Does Earth's magnetic field secular variation control centennial climate change?, Earth Planet. Sci. Lett., 236, 339-347, 2005.

Genevey, A. and Y. Gallet, Intensity of the geomagnetic field in western Europe over the past 2000 years: New data from ancient French pottery, J. Geophys. Res., 107(B11), 2285, 2002.

Genevey, A. S., Y. Gallet, and J. C. Margueron, Eight thousand years of geomagnetic field intensity variations in the eastern Mediterranean, $J$. Geophys. Res., 108(B5), 2228, 2003.

Gómez-Paccard, M., A. Chauvin, Ph. Lanos, J. Thiriot, and P. JiménezCastillo, Archeomagnetic study of seven contemporaneous kilns from Murcia (Spain), Phys. Earth Planet. Inter., 157, 16-32, 2006.

Gubbins, D., A. L. Jones, and C. C. Finlay, Fall in Earth's Magnetic Field is Erratic, Science, 312, 900-902, 2006.

Jackson, A., A. R. T. Jonkers, and M. Walker, Four centuries of geomagnetic secular variation from historical records, Phil. Trans. R. Soc. London A, 358, 957-990, 2000.

Korte, M. and C. G. Constable, Continuous geomagnetic field for the past 7 millennia: 2.CALS7K, Geochem. Geophys. Geosyst., 6, 1, 2005.

Korte, M., A. Genevey, C. G. Constable, U. Frank, and E. Schnepp, Continuous geomagnetic field models for the past 7 millennia: 1 . A new global data compilation, Geochem. Geophys. Geosyst., 6, Q02H15, 2005.

Kovacheva, M., Archeomagnetic database from Bulgaria: the last 8000 years, Phys. Earth Planet. Inter., 102, 145-151, 1997.

Kovacheva, M., J. M. Parés, N. Jordanova, and V. Karloukovski, A new contribution to the archaeomagnetic study of a Roman pottery kiln from Calahorra (Spain), Geophys. J. Int., 123, 931-936, 1995.

McIntosh, G., M. Kovacheva, G. Catanzariti, M. L. Osete, and L. Casas, Widespread occurrence of a novel high coercivity, thermally stable, low unblocking temperature magnetic phase in heated archeological material, Geophys. Res. Lett., 34, L21302, 2007.

Morales, J., A. Goguitchaichvili, and J. Urrutia-Fucugauchi, A rockmagnetic and paleointensity study of some Mexican volcanic lava flows during the Latest Pleistocene to the Holocene, Earth Planets Space, 53, 893-902, 2001.

Morales, J., L. M. Alva-Valdivia, A. Goguitchaichvili, and J. UrrutiaFucugauchi, Cooling rate corrected paleointensities from the Xitle lava flow: Evaluation of within-site scatter for single spot-reading cooling units, Earth Planets Space, 58, 1341-1347, 2006.

Néel, L., Some theoretical aspects of rock magnetism, Adv. Phys., 4, 191243, 1955.

Perrin, M. and E. Schnepp, IAGA paleointensity database: distribution and quality of the data set, Phys. Earth Planet. Inter., 147, 255-267, 2004.

Soler-Arechalde, A. M., F. Sanchez, M. Rodriguez, C. Caballero-Miranda, A. Goguitchaichvili, J. Urrutia-Fucugauchi, L. Manzanilla, and D. $\mathrm{H}$. Tarling, Archaeomagnetic investigation of oriented pre-Columbian lime-plasters from Teotihuacan, Mesoamerica, Earth Planets Space, 58, 1433-1439, 2006.

Thellier, E. and O. Thellier, Sur l'intensité du champ magnetiqué terrestre dans le passé historique et géologique, Ann. Geophys., 15, 285-376, 1959.

Valet, J.-P., Time Variations in Geomagnetic Intensity, Rev. Geophys., 41, $1,2003$.

Yu, Y., D. J. Dunlop, L. Pavlish, and M. Cooper, Archeomagnetism of Ontario potsherds from the last 2000 years, J. Geophys. Res., 105(B8), 19419-19434, 2000.

G. A. Hartmann (e-mail: gelvam@iag.usp.br), R. I. F. Trindade, A. Goguitchaichvili, C. Etchevarne, J. Morales, and M. C. Afonso 